\title{
OY-TES-1 expression and serum immunoreactivity in epithelial ovarian cancer
}

\author{
JONATHAN TAMMELA ${ }^{1}$, AKIKO UENAKA ${ }^{5}$, TOSHIRO ONO ${ }^{6}$, YUJI NOGUCHI ${ }^{5}$, ACHIM A. JUNGBLUTH ${ }^{7}$, \\ PAULETTE MHAWECH-FAUCEGLIA ${ }^{4}$, FENG QIAN ${ }^{1,2}$, SALLY SCHNEIDER ${ }^{2}$, SAMEER SHARMA ${ }^{1}$, \\ DEBORAH DRISCOLL ${ }^{3}$, SHASHIKANT LELE ${ }^{1}$, LLOYD J. OLD $^{7}$, EIICHI NAKAYAMA ${ }^{5}$ and KUNLE ODUNSI ${ }^{1,2}$ \\ Departments of ${ }^{1}$ Gynecologic Oncology, ${ }^{2}$ Immunology, ${ }^{3}$ Biostatistics, and ${ }^{4}$ Pathology, Roswell Park Cancer Institute Buffalo, \\ NY, USA; ${ }^{5}$ Department of Immunology, Okayama University Graduate School of Medicine and Dentistry, Okayama, Japan; \\ ${ }^{6}$ Department of Radiation Research, Okayama University Advanced Science Research Center; ${ }^{7}$ Ludwig Institute \\ for Cancer Research, New York Branch at Memorial Sloan-Kettering Cancer Center, New York, NY, USA
}

Received March 30, 2006; Accepted May 19, 2006

\begin{abstract}
O Y$-TES- 1 is a novel target that belongs to the family of 'cancer/testis' (CT) antigens. Our goal was to examine the expression and immunogenicity of $O Y-T E S-1$ in epithelial ovarian cancer (EOC) to determine its potential as a target for vaccine therapy. OY-TES-1 expression was determined by one-step reverse transcriptase PCR on 100 EOC samples, 5 EOC cell lines, and a panel of normal tissues. Immunohistochemistry (IHC) was performed on the same panel of EOC tissues. Sera from a sub-group of patients were tested for $O Y$-TES- 1 antibody by ELISA. Thymus and leukocytes were weakly positive for $O Y$-TES- 1 while the remaining 5 normal tissues were negative. Expression of $O Y-T E S-1$ by either RT-PCR and/or IHC was demonstrable in 69/100 (69\%) tumors. Humoral immunity to $O Y-T E S-1$ was demonstrated in $1 / 10(10 \%)$ serum samples from patients whose tumors expressed the antigen. The median follow-up of the patient population was 34 months. There was no correlation between antigen expression and stage, grade, histology and survival. OY-TES- 1 is expressed in $69 \%$ of patients with EOC, is absent from normal ovarian tissue, and a proportion of patients show evidence of a specific humoral immune response. These findings make $O Y-T E S-1$ an attractive target for antigen-specific immunotherapy in EOC.
\end{abstract}

\section{Introduction}

Ovarian cancer is the leading cause of death in women with gynecologic malignancies (1). The majority of patients are diagnosed at an advanced stage, and despite modest

Correspondence to: Dr Kunle Odunsi, Divisions of Gynecologic Oncology, Roswell Park Cancer Institute, Buffalo, NY 14263, USA E-mail: kunle.odunsi@roswellpark.org

Key words: ovarian tumor antigen, immunogenicity, immunohistochemistry, antibody, prognostic indicator improvements in survival with the use of adjuvant chemotherapy with platinum/paclitaxel based chemotherapy, overall survival for patients with advanced epithelial ovarian cancer (EOC) remains poor (2). A potential strategy for improving outcome in patients with EOC is to minimize recurrence by utilizing the immunotherapy approach in those that show complete response to front-line therapy. These patients can be presumed to have micrometastatic disease that can potentially be recognized by the immune system and lead to an improvement in remission rates. This approach requires the identification and characterization of tumor antigens with high frequency expression in tumor tissues, restricted expression in normal tissues, and inherent immunogenicity. As a consequence of advances in approaches for analyzing immune reactivity to cancer in the context of the autologous host, a number of human tumor antigens have been identified. These antigens are categorized into various classes such as differentiation antigens [e.g. tyrosinase (3)], mutational antigens [e.g. P53 (4)], amplified antigens [e.g. Her2/neu (5)], splice variant antigens [e.g. NY-CO-37/PDZ-45 (4)], viral antigens [e.g. HPV (6)], and cancer-testis (CT) antigens [e.g. MAGE (7), NY-ESO-1 (8) and OY-TES-1 (9)].

The 'cancer-testis' (CT) antigens are a unique class of antigens that demonstrate high levels of expression in adult male germ cells, but generally not in other normal adult tissues, and aberrant expression in a variable proportion of a wide range of different cancer types (10-12). This fact makes CT antigens especially attractive targets for specific immunotherapy. The expression of a number of CT antigens has been investigated in EOC. NY-ESO-1 is expressed in $40 \%$ (13), MAGE-Al in $20 \%$ (14), MAGE-A3 in 20\% (14), MAGE-A4 in $~ 57 \%$ (15), and SCP-1 in $15 \%$ (16). OY-TES-1 was identified as an additional member of the cancer/testis family of antigens (9). OY-TES- 1 is the human homologue of proacrosin binding protein sp32 precursor originally identified in mouse, guinea pig, and pig (17), and maps to human chromosome 12p12-p13.

The aim of the present study was to determine the frequency of expression of $O Y-T E S-1$ mRNA and protein in epithelial ovarian cancer. We also examined the spontaneous antibody 
response against $O Y-T E S-1$ in a subset of EOC patients. A secondary objective was to examine the relationship between $O Y$-TES- 1 expression and clinical outcome. Our results showed a high frequency of $O Y-T E S-1$ expression in EOC, and would suggest that $O Y$-TES- 1 is a promising candidate for specific immunotherapy in epithelial ovarian cancer.

\section{Materials and methods}

Patients and specimens. Formalin-fixed paraffin-embedded and flash frozen tissue specimens were obtained from patients undergoing debulking surgery for epithelial ovarian cancer at the Roswell Park Cancer Institute, Buffalo, NY between 1995 and 2003. All tissue specimens were collected under an approved protocol from the Institutional Review Board (IRB). All pathology specimens were reviewed in our institution and tumors were classified according to WHO criteria (18). In a subset of patients, serum samples were also available over extended periods of time during the course of disease. The medical records of the patients were also retrospectively reviewed under an approved IRB protocol. The review included outpatient and inpatient treatment, including surgery and chemotherapy. Study outcomes included overall survival and time to progression, each measured from the time of definitive surgery. Progression was defined as objective evidence of recurrence, since all therapy was given in the adjuvant setting. The duration of overall survival was the interval between diagnosis and death. Observation time was the interval between diagnosis and last contact (death or last follow-up). Data were censored at the last follow-up for patients with no evidence of recurrence or progression.

Cell lines. Five ovarian cancer cell lines were purchased from the American Type Culture Collection and grown in the recommended media under standard conditions. These were SVOV3, OVCA-429, OVCA-432, SK-OV-3, and OVCAR-3. The immortalized human normal ovarian surface epithelial cell lines, IOSE and HOSE were grown in the recommended media under standard conditions. These were gifts from Dr Nancy Auersperg (University of British Columbia, Vancouver, BC), and Dr Sam Mok (Harvard University, Boston, MA) respectively. Normal human tissue RNAs were obtained from Clontech (Palo Alto, CA) or isolated from the tissues obtained from the Tissue Procurement Facility of the Roswell Park Cancer Institute. The normal tissue RNAs from Clontech are from a mixture of tissues from a number of individuals who died of trauma.

Total tissue RNA isolation. Total tissue RNA was isolated from frozen tumor tissues and from ovarian cancer cell lines, using the TRIReagent (Molecular Research Center Inc., Cincinnati, $\mathrm{OH}$ ) according to the manufacturer's protocol. Potentially contaminating DNA was removed by treating with RNase-free DNase I (Boehringer-Mannheim, Mannheim, Germany). After phenol treatment and drying, RNA was dissolved in RNase-free $\mathrm{H}_{2} \mathrm{O}$. The resulting RNA concentration was measured spectrophotometrically (GeneQuant; Amersham Pharmacia Biotech Ltd., Cambridge, UK), and the quality of the RNAs was checked by electrophoresis on $1 \%$ agarose gel.
RT-PCR analysis of OY-TES-1 expression. Two micrograms of each RNA sample were subjected to cDNA synthesis using the Ready-To-Go first strand synthesis kit (Pharmacia, Uppsala, Sweden). PCR was subsequently performed to analyze expression of OY-TES-1. A 604-bp long OY-TES-1 specific PCR product was amplified using OY-TES-1 specific sense 5'-AAGGACAGGGGACTAAGGAG-3' and antisense 5'-CCGTACAAATCCAGCCCGTA-3' primers (9). Glyceraldehyde-3-phosphodehydrogenase (GAPDH) specific sense 5'-GCTTCCCGTTCCTCAATTTTGAAG-3' and antisense 5'-ATGGGAAGGTGAAGG-TCGGAG-3' primers were used to obtain a 195-bp PCR product as a control. PCR was performed in a PTC-100 (Programmable Thermal Controller, MJ Research, Inc.) and included 60 -min incubation at $50^{\circ} \mathrm{C}$ for reverse transcription and 15 min for enzyme inactivation at $95^{\circ} \mathrm{C}$, followed by 30 cycles of PCR. Each PCR cycle consists of a 1-min denaturation at $94^{\circ} \mathrm{C}$ followed by a 30 -sec annealing at $62^{\circ} \mathrm{C}$ and $1-\mathrm{min}$ and $30-\mathrm{sec}$ extension at $72^{\circ} \mathrm{C}$. After the last cycle, the final extension step was at $72^{\circ} \mathrm{C}$ for $10 \mathrm{~min}$. The PCR products were visualized by ethidium bromide staining after separation over a $1.5 \%$ agarose gel.

Recombinant OY-TES-1 protein. OY-TES-1 was expressed in Escherichia coli by using the histidine-tag-containing vector pQE30 (Qiagen). cDNA amplification primers were designed to encompass the entire coding sequence of the gene, corresponding to amino acid positions 1-543. Induction of recombinant protein synthesis and subsequent purification by $\mathrm{Ni}^{2+}$-NTA column were performed according to the manufacturer's instructions (9). A truncated or short protein (N-terminal half, Q26-R273) was also expressed in E. coli by using the histidine-tag-containing vector pQE30 (Qiagen).

Generation of mouse hybridomas. BALB/c female mice were inoculated intra-muscularly with pCIneo-OY-TES-1 plasmid $(30 \mu \mathrm{g})$ twice at an interval of 2 weeks, followed 1 month later by boosting with the truncated N-half OY-TES-1 protein (Q26-R273) (10 $\mu \mathrm{g})$ intravenously. Spleen cells from immunized mice fused with mouse myeloma cell line NS-1, and supernatants from sequentially cloned populations were screened against the immunizing protein by solid phase ELISA (19).

Immunohistochemistry (IHC). Tumor specimens were fixed with buffered-formalin and embedded in paraffin. Sections $(5 \mu \mathrm{m})$ were placed on glass slides, heated at $60^{\circ} \mathrm{C}$ for $20 \mathrm{~min}$, and then deparaffinized with xylene and ethanol. For antigen retrieval, tumor specimens mounted on glass slides were immersed into preheated antigen retrieval solution (Dako high $\mathrm{pH}$ solution, Capinteria, CA) for $20 \mathrm{~min}$ and allowed to cool for $20 \mathrm{~min}$ at room temperature. After the inactivation of endogenous peroxidase, mAb to OY-TES-1 (clone UA-199) was then added at a concentration of $2.5 \mu \mathrm{g} / \mathrm{ml}$ and incubated overnight at $4^{\circ} \mathrm{C}$. The primary antibody was detected with a biotinylated anti-mouse IgG (Dako, Capinteria, CA). Diaminobenzidine tetrahydrochloride was then added for development for $10 \mathrm{~min}$, followed by counterstaining with hematoxylin solution.

The extent of immunohistochemical reactivity was graded as follows: negative, focal, staining of single cells or small 
clusters of cells $(\sim<5 \%$ cells stained);,$+ 5-25 \% ;++,>25-50 \%$; ,$+++>50-75 \%$; and,$++++>75 \%$ of cells stained. Negative control slides omitting the primary antibody were included in all assays.

ELISA. Recombinant OY-TES-1 protein $(2 \mu \mathrm{g} / \mathrm{ml})$ in $0.05 \mathrm{M}$ carbonate buffer ( $\mathrm{pH}$ 9.6) was absorbed to 96-well plates (Nunc, Roskilde, Denmark) at $4^{\circ} \mathrm{C}$ overnight. Plates were washed with PBS/Tween and blocked with $5 \% \mathrm{FCS} / \mathrm{PBS}$ at room temperature for $1 \mathrm{~h}$. After washing, serum dilutions $(100 \mu \mathrm{l})$ in $5 \%$ FCS/PBS were added and incubated at room temperature for $2 \mathrm{~h}$. Plates were washed and incubated with secondary antibody (goat anti-human IgG-AP; Southern Biotechnology, Birmingham, AL) at 1/2,000 dilution for $1 \mathrm{~h}$ at room temperature. Plates were washed and incubated with the substrate solution (1,2-phenylenediamine dihydrochloride) for $20 \mathrm{~min}$ at room temperature. After addition of $3 \mathrm{M} \mathrm{H}_{2} \mathrm{SO}_{4}$ (100 $\mu 1$ ), the absorbance was determined with a microplate reader (Tosoh, Tokyo). Sera were tested over a range of 4-fold dilutions from 1:100 to 1:100,000, as described previously (20).

Statistical analysis. All statistical analyses were performed with the SPSS software (21). Statistical correlations were calculated using Pearson's R Product Moment Correlation Coefficient. The distribution of OY-TES-1 expression and clinical outcome was analyzed by the $\chi^{2}$ test. Estimated survival distributions were calculated by the method of Kaplan and Meier (22) and tests of significance with respect to survival distributions were based on the log-rank test (23). No adjustments were made for multiple comparisons.

\section{Results}

Study population. The characteristics of the study population are presented in Table I. The median age of the study population was 64 years (range 26-89 years) and the median duration of follow-up was 34 months (range 0.36-131 months). As expected, the majority of patients presented with grade 3 tumors $(85 \%)$, at stage IIIC $(69 \%)$ and with serous differentiation (74\%). A complete response to therapy was achieved in 57 of the 100 patients (57\%); a partial response was achieved in 40 patients $(40 \%)$ while the remaining patients had no response. The median estimated overall survival for all patients was 50 months (95\% CI 36-64 months) while the median disease-free survival, excluding patients with persistent/ progressive disease after initial therapy, was 37 months (95\% CI 4-69 months).

Expression of OY-TES-1 mRNA in normal tissues, cell lines and EOC specimens. Expression of OY-TES-1 mRNA in a panel of normal tissues, immortalized normal ovarian surface epithelial cell lines (IOSE and HOSE), ovarian cancer cell lines and epithelial ovarian tumor specimens was investigated by RT-PCR. Intensities of PCR products in tumor specimens were found to be heterogeneous, and some specimens yielded only faint amplicons. These were scored positive only if the result could be reproduced by a repeated RNA extraction and specific RT-PCR from the same tumor specimen. Cases with very low transcript levels, which were not reproducibly positive, were not regarded as positive. The normal ovarian
Table I. Patient characteristics.

\section{Characteristics}

Evaluable patients

100

Age (median/range), years

$64(26-89)$

Follow-up (median /range), months ${ }^{\mathrm{a}}$

$34(36-131)$

Grade, $\mathrm{n}$

1

2

6

3

8

85

FIGO stage, n (\%)

$\begin{array}{lrc}\text { IA } & 4 & (4) \\ \text { IB } & 1 & (1) \\ \text { IC } & 3 & (3) \\ \text { IIA } & 1 & (1) \\ \text { IIB } & 1 & (1) \\ \text { IIC } & 5 & (5) \\ \text { IIIA } & 1 & (1) \\ \text { IIIB } & 2 & (2) \\ \text { IIIC } & 74(74) \\ \text { IV } & 8 & (8)\end{array}$

Histology, n (\%)

Papillary serous

Clear cell

Endometroid

Mucinous

Undifferentiated

Others (transitional, mixed, carcinosarcoma)

Response to frontline therapy, n (\%)

Complete response

Partial response

Progression

Unknown

Recurrences $^{\mathrm{b}}, \mathrm{n}(\%)$

Recurrence/persistent disease

Current status, n (\%)

Alive, NED ${ }^{c}$

Alive with disease

Dead of disease

$51(51)$

Dead from other causes

0

Antigen status (RT-PCR and/or IHC), n (\%)

OY-TES-1 positive (either method)

OY-TES-1 positive (RT-PCR only)

OY-TES-1 positive (IHC only)

$60(63)$

aMedian survival for all patients: 50 months (CI 36-64 months) ${ }^{\mathrm{b}}$ Median disease-free survival (excluding patients with persistent disease): 37 months (4-69 months). ${ }^{\mathrm{c} N E D}$, no evidence of disease. 
Table II. Correlation between OY-TES-1 IHC expression and and clinico-pathological features in epithelial ovarian cancer.

\begin{tabular}{lcc}
\hline Pathological and clinical features & Positive & Negative \\
\hline Evaluable patients $(\mathrm{n}=100)$ & $60(60 \%)^{\mathrm{a}}$ & $40(40 \%)$ \\
Age (median/range), years & $64(26-89)$ & $64(29-85)$
\end{tabular}

Grade, n (\%)

$\begin{array}{rrr}1 & 4 & 2 \\ 2 & 6 & 2 \\ 3 & 50 & 31\end{array}$

\section{FIGO stage, n (\%)}

$1 \mathrm{~A}$

1B

$1 \mathrm{C}$

IIA

IIB

IIC

IIIA

IIIB

IIIC

IV

Histology, n

Papillary serous

Clear cell

Endometroid

Mucinous

Undifferentiated

Others (transitional,

mixed, carcinosarcoma)

Response to frontline therapy,

$$
\text { n }(\%)
$$

Complete response

\begin{tabular}{|c|c|}
\hline $37(62)$ & $17(48)$ \\
\hline $22(37)$ & $16(46)$ \\
\hline 0 & 1 (3) \\
\hline 1 (1) & 1 (3) \\
\hline
\end{tabular}

Partial response

Progression

Unknown

$\begin{array}{rr}43 & 26 \\ 3 & 4 \\ 4 & 1 \\ 1 & 1 \\ 3 & 0 \\ 6 & 3\end{array}$

Recurrences $^{\mathrm{b}}, \mathrm{n}(\%)$

Recurrence/persistent disease

Current status, n (\%)

\begin{tabular}{|c|c|c|}
\hline Alive, $\mathrm{NED}^{\mathrm{c}}$ & $21(35)$ & $10(29)$ \\
\hline Alive with disease & $11(18)$ & $5(14)$ \\
\hline Dead of disease ${ }^{\mathrm{d}}$ & $28(47)$ & $20(57)$ \\
\hline
\end{tabular}

${ }^{\mathrm{a}}$ Focal, $<5 \%$ (37\% of patients);,$+<25 \%$ (17\% of patients); ++ , $>25-50 \%$ ( $14 \%$ of patients);,$+++>50-75 \%$ ( $11 \%$ of patients); ,$++++>75 \%$ ( $14 \%$ of patients). ${ }^{\text {bProgression-free survival for }}$ patients with OY-TES-1 mRNA-negative tumor was 39 (CI 8, 69) months and 37 (CI 1,72) months for IHC-positive patients ( $\mathrm{p}=0.82)$. ${ }^{\mathrm{c}} \mathrm{NED}$, no evidence of disease. ${ }^{\mathrm{d}}$ Median survival for patients with OY-TES-1 mRNA-negative tumors was 44 (CI 28,59) months and 50 (CI 34, 66) months for IHC-positive patients $(\mathrm{p}=0.38)$.

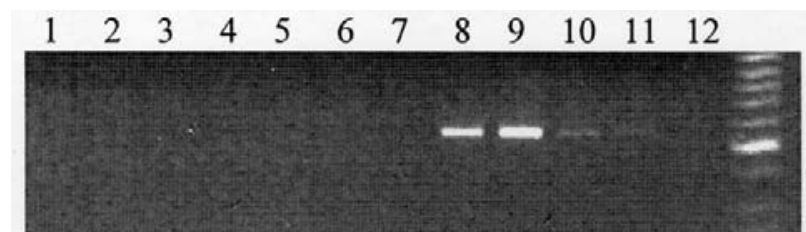

OY-TES-1

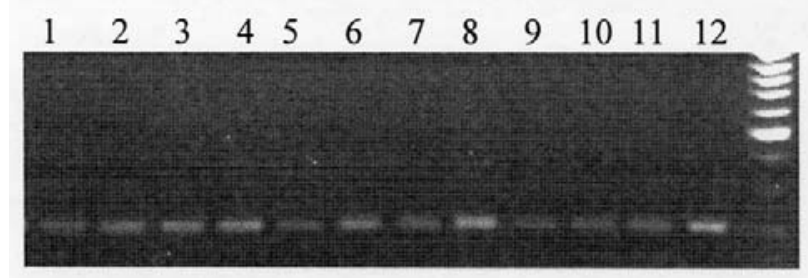

GAPDH

Figure 1. RT-PCR analysis for OY-TES-1 mRNA expression. Shown is mRNA from EOC specimens (lanes 1-6, negative), normal ovary (lane 7, negative), Testis (lane 8, positive), EOC specimens (lane 9-11, positive), EOC specimen (lane 12, negative). GAPDH, glyceraldehyde-3-phosphate dehydrogenase.

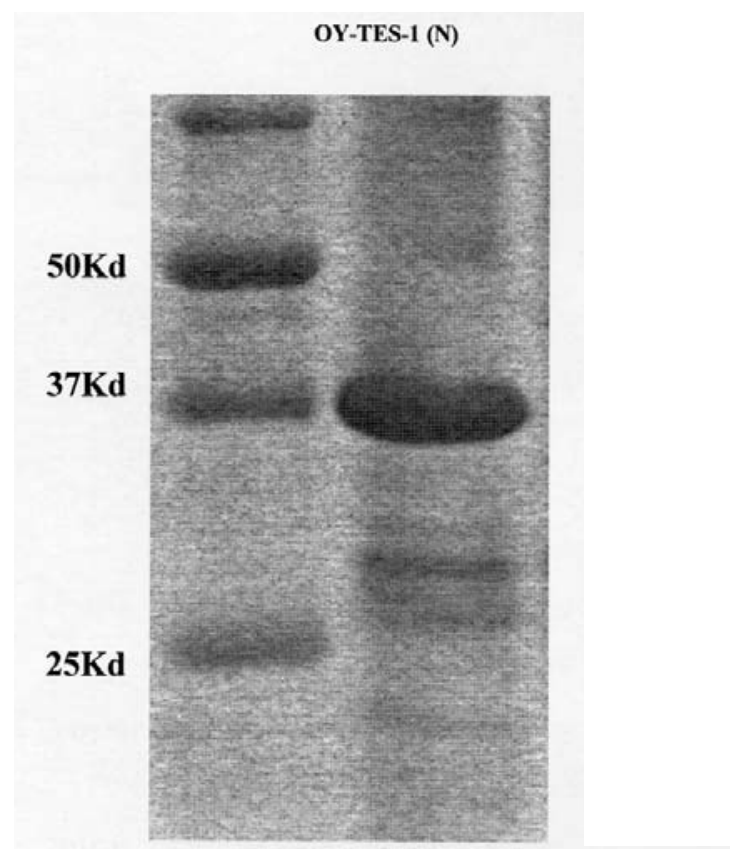

Figure 2. SDS-PAGE of recombinant OY-TES-1 protein (N-terminal half).

surface epithelial cell lines, IOSE and HOSE, did not express OY-TES-1. The normal tissue panel consisting of ovary, colon, spleen, prostate, and small intestine did not express OY-TES-1. The thymus and leukocyte were weakly positive. Also, one of the five ovarian cancer cell lines, SKOV3, was positive for the antigen while the remaining were negative. OY-TES-1 mRNA expression was detected in 23/100 (23\%) of tumor specimens (Fig. 1).

Production of recombinant OY-TES-1 protein and mouse $m A b s$. The truncated $\mathrm{N}$-terminal half protein was used for the generation of mouse monoclonal antibodies for immuno- 

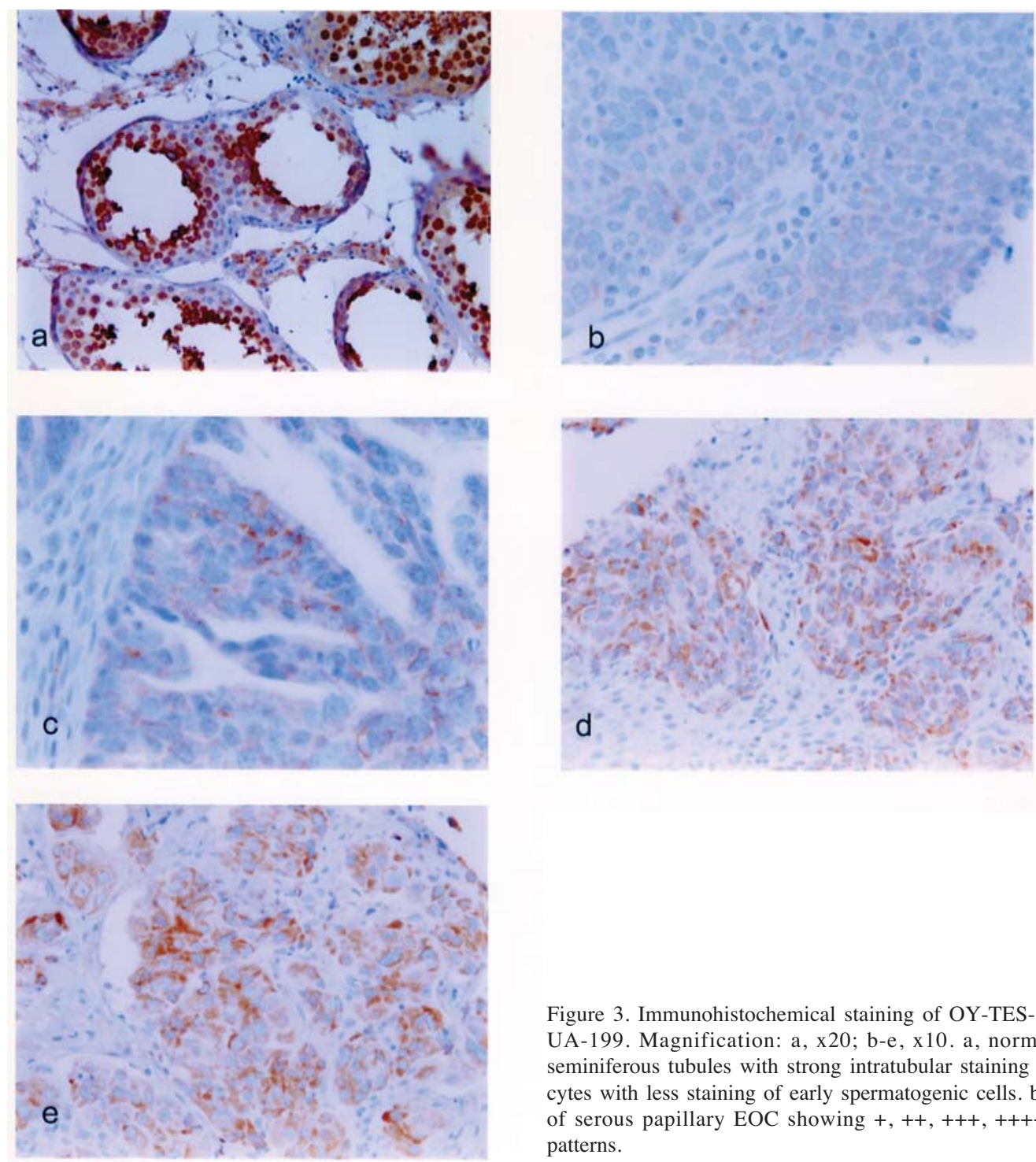

Figure 3. Immunohistochemical staining of OY-TES-1 antigen with $\mathrm{mAb}$ UA-199. Magnification: a, x20; b-e, x10. a, normal testis indicating seminiferous tubules with strong intratubular staining of mostly spermatocytes with less staining of early spermatogenic cells. b-e, UA-199 staining of serous papillary EOC showing,,,++++++++++ immunoreactivity patterns.
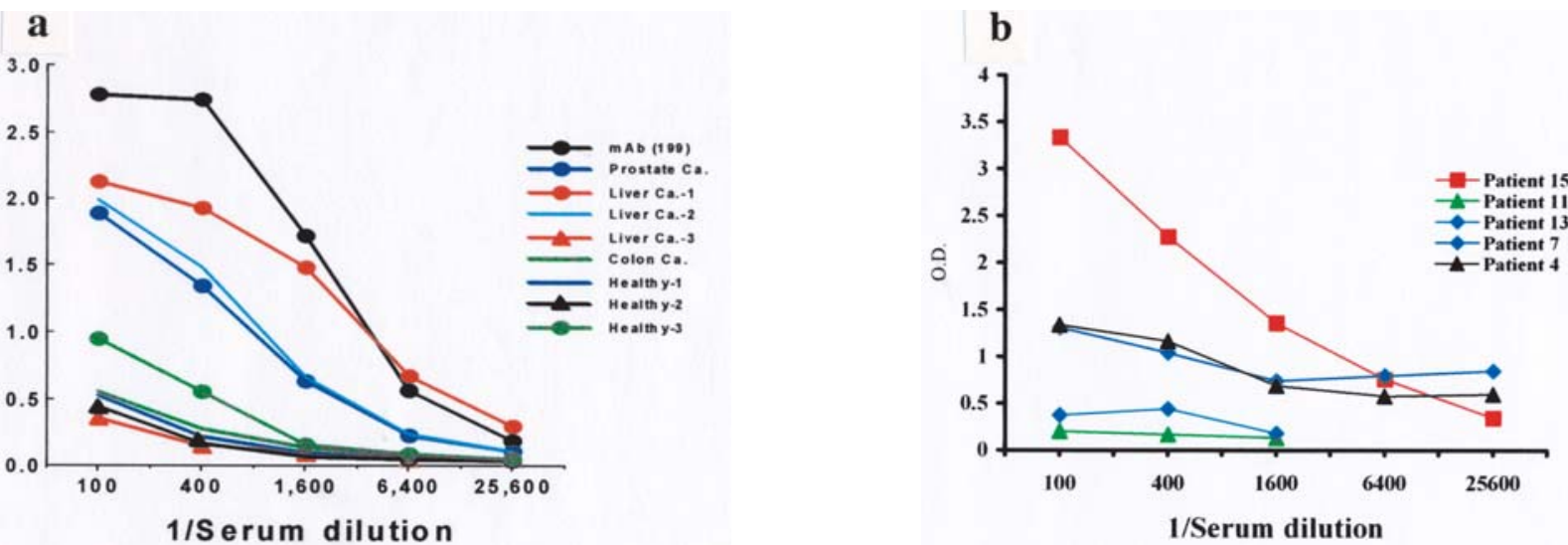

Figure 4. ELISA reactivity of recombinant OY-TES-1 protein (N-terminal half) in patients and healthy controls. Mab UA-199 was used as positive control. Two patients with liver cancer (liver ca-1 and liver ca-2) and one patient with prostate cancer demonstrated serum immunoreactivity to OY-TES-1. b, ELISA reactivity of recombinant OY-TES-1 protein in ovarian cancer patients. Patient 15 demonstrated antibody response against OY-TES-1.

histochemistry. Four hybridoma clones, designated UA-11, UA-60, UA-144 and UA-199, secreting mAbs that showed reactivity against recombinant $O Y$-TES-1 were harvested and subcloned. UA-199 exhibited the highest titer against
OY-TES-1 recombinant protein in ELISA and was used for immunohistochemistry. The purified truncated protein had an apparent molecular weight of $37 \mathrm{kDa}$ by SDS-PAGE (Fig. 2), and was used for ELISA. 


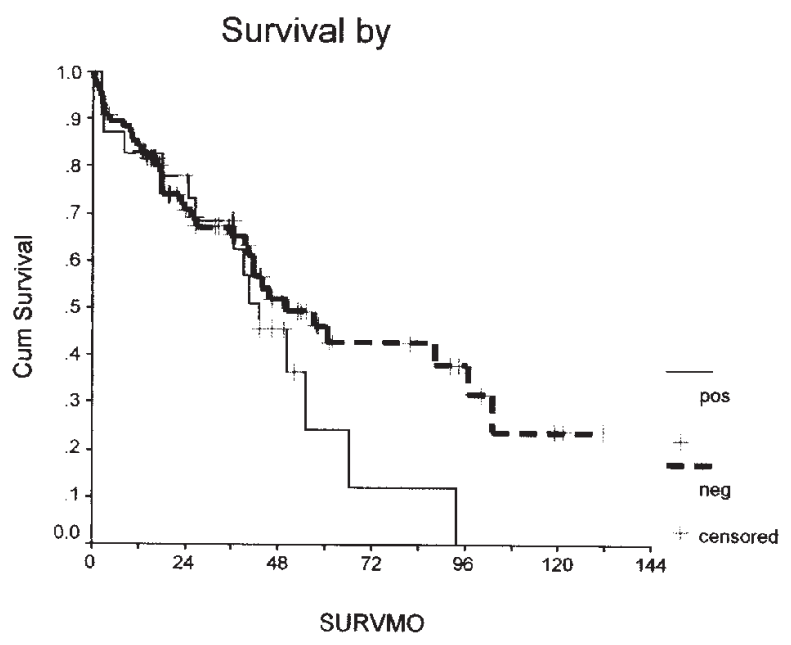

Figure 5. Kaplan-Meier estimates of overall survival in EOC patients according to tumor expression of OY-TES-1.

Expression of OY-TES-1 by immunohistochemistry. OY-TES-1 exhibited intense immunostaining of the germ cells of the testis (Fig. 3a). Our results indicate that seminiferous tubules had strong intratubular staining of mostly spermatocytes with less staining of early spermatogenic cells. This is consistent with the location of the protein in the sperm acrosome of other species (9). There was no reactivity with Sertoli cell or interstitial tissue. There was also no reactivity in a panel of normal tissues consisting of brain, heart, lung, skeletal muscle, kidney, ovary and stomach.

Positive staining was observed in 60 of 100 (60\%) archived, formalin-fixed, paraffin-embedded ovarian cancer samples. Reactivity was mostly heterogeneous, i.e., present in discrete areas of the tumors (focal or '+' staining according to our grading). Fig. 3b-e is an example of the observed staining patterns. The predominant expression pattern was heterogenous (focal,,+++ ), occurring in 42/60 (70\%) of OY-TES-1-positive specimens, while the remaining 18/60 (30\%) demonstrated +++ or ++++ staining. Expression of $O Y-T E S-1$ by either RT-PCR and/or IHC was demonstrable in 69/100 (69\%) tumors.

Antibody response to OY-TES-1 in ovarian cancer patients. The ELISA reactivity of the full-length recombinant protein and the truncated N-terminal OY-TES-1 protein was assessed. We observed the same serum reaction against both full-length and N-terminal polypeptide. A representative serum reactivity pattern against the N-terminal half of the OY-TES-1 protein in a panel of healthy controls and patients with liver, prostate and colon cancers is shown in Fig. 4a. Two patients with liver cancer, and a patient with prostate cancer demonstrated an antibody response to $O Y-T E S-1$.

A total of 21 pre-operative serum samples were analyzed by ELISA for $O Y$-TES- 1 antibody. Ten of the serum samples were from patients whose tumors expressed OY-TES-1, while the rest were from $O Y-T E S-1$ negative patients. There was a demonstrable antibody response to $O Y-T E S-1$ in $1 / 10$ (10\%) patients with OY-TES-1 expressing tumors. All of the patients without OY-TES-1 expressing tumors were also negative by ELISA. The patient that had an antibody response had expression of $O Y-T E S-1$ that was $3+$ positive by IHC. Fig. 4b illustrates titration curves with sera from selected ovarian cancer patients.

Correlation of OY-TES-1 expression with clinical outcome. Patients whose tumors expressed $O Y$-TES-1 by RT-PCR and/or IHC had a median disease-free survival of 22 months (95\% CI 13-30 months) compared with 39 months (95\% CI 2-75 months) among patients whose tumors did not express $O Y$-TES- $1 \quad(\mathrm{p}=0.43)$. Patients whose tumors expressed $O Y$ TES- 1 had a trend towards worse median overall survival of 43 months (95\% CI 31-55 months) compared to 50 months (95\% CI 32-68) among patients whose tumors did not express OY-TES-1 (p=0.20) (Fig. 5). When all patients with tissue expression of $O Y-T E S-1$ were considered, no significant correlation was observed with stage, grade, histology, diseasefree or overall survival. The single patient with evidence of specific humoral immune response to OY-TES-1 initially had optimal surgical debulking of stage IIIC papillary serous of the ovary, and is alive without evidence of disease, 40 months after initial adjuvant carboplatin and paclitaxel chemotherapy.

\section{Discussion}

One of the major barriers to antigen-specific immunotherapy in epithelial ovarian cancer (EOC) is the lack of well-defined immunogenic tumor antigens. The need to identify and characterize tumor antigens in EOC has become even more compelling because of recent evidence demonstrating that the presence of intratumoral $\mathrm{T}$ cells correlates with improved clinical outcome $(24,25)$, suggesting that efforts to stimulate and/or augment the anti-tumor immune response are likely to be of particular benefit in this disease. In order to assess the utility of $O Y$-TES-1, a new member of the CT family of antigens as a target for specific immunotherapy of EOC, we utilized conventional RT-PCR for mRNA expression and generated antibody for protein expression. Our results indicate aberrant expression of OY-TES-1 mRNA and protein in 23 of $100(23 \%)$ and 60/100 (60\%) of EOC specimens respectively. The frequency of $O Y-T E S-1$ expression in ovarian cancer observed in our study is higher than the reported frequency of expression of other CT antigens in ovarian cancer $(13-15,26)$. In a separate recent study of OY-TES-1 expression in other cancer tissues, we detected OY-TES- 1 mRNA in 3/20 breast cancers, 2/5 liver cancers, 1/20 lung cancers, 2/38 colon cancers, $0 / 5$ stomach cancers, $0 / 10$ renal cancers, 4/18 ovarian cancers, and 5/20 endometrial cancers in the Japanese population (Nakayama E, personal communication).

In our study, we observed a discrepancy in the frequency of expression of OY-TES-1 at the mRNA and protein levels. Since the antibody used in our study (UA-199) stained normal human testes (positive control) appropriately, and did not stain a panel of other normal tissues, the relatively high frequency of expression by IHC is unlikely to be due to issues of antibody specificity. Additionally, only 13 of the 60 tumors that were classified as positive by IHC had a focal staining pattern. While it is possible that the relatively large amplicon size of the OY-TES- 1 mRNA was not detectable in our RT-PCR analysis of some of the tumor tissues, our results may also reflect tumor heterogeneity with regards 
to antigen expression. Alternatively, IHC may be identifying an alternatively spliced protein or a truncated protein that the primers used in RT-PCR are not able to detect. These findings suggest that both RT-PCR and IHC analysis are important in the assessment of OY-TES-1 expression in tumor tissues.

In an effort to determine the inherent immunogenicity of $O Y$-TES- 1 in patients with EOC, we studied a subset of 21 patients where tumor and serum specimens from the same patients were available. Of these twenty-one patients, ten had OY-TES-1-positive tumors. The results showed that OY-TES-1 antibody was found in $10 \%(1 / 10)$ of patients with $O Y$-TES-1-positive tumors. In a survey of sera from 70 normal individuals and 234 cancer patients for antibodies against a panel of CT antigens, Stockert et al (20) reported NY-ESO-1 antibodies in 19 patients (four with EOC), MAGE-1 antibodies in three patients (one with melanoma, one with EOC, and one with lung cancer), MAGE-3 antibody in two patients (both with melanoma), and SSX2 antibody in one patient with melanoma. No antibody against any of the CT antigens was found in healthy individuals. Although we have not tested antigen-specific $\mathrm{CD}^{+} \mathrm{T}$ cell responses to $O Y-T E S-1$ in the current study, parallel results for NY-ESO-1 indicate that a humoral immune response to NY-ESO-1 was predictive of a strong $\mathrm{CD}^{+} \mathrm{T}$ cell response (27). Clearly, the analysis of $O Y$-TES-1-specific cytotoxic T cells in EOC is warranted to shed additional light on the nature of the spontaneous immune response to this antigen.

$O Y-T E S-1$ is a proacrosin binding protein sp32 precursor thought to be involved in packaging acrosin in the acrosome in the sperm head and the antigen of interest in this study. While OY-TES- 1 has a known role in gametogenesis, its role in cancer, along with the majority of the other CT antigens, is unknown. Although the lack of correlation between OY-TES-1 expression and clinico-pathologic characteristics (histologic type, tumor grade, recurrence and survival) may reflect the fact that the majority of the patients (Table I) had advancedstage disease, it may also imply that the antigen is not critical for tumor progression. Interestingly, Scanlan et al (12) have shown that $11 / 13$ non-gametogenic tissues examined showed moderate to high levels (0.1-2.0 mcg cDNA product detected) of $O Y$-TES- 1 expression by RT-PCR compared to high levels ( $>2.0 \mathrm{mcg}$ cDNA product tested) in the testis. In addition, Kubuschok et al (28) recently demonstrated expression of OY-TES-1 by RT-PCR in 11/12 normal tissues (adrenal gland, bladder, brain, endometrium, liver, lymph node, ovary, small intestine, stomach, thyroid and tonsil); and in 5/6 non-malignant pancreatic tissues ( 2 specimens of normal pancreas and 4 of chronic pancreatitis). While these findings call into question the classification of $O Y-T E S-1$ as a CT antigen, the tissue restricted distribution and inherent immunogenicity support the notion that $O Y-T E S-1$ could be a valuable vaccine target in EOC. Indeed, the only patient with antibody response to OY-TES-1 has demonstrated an unusually favorable course with no evidence of disease after 40 months of follow-up. This finding underscores the need for additional analysis to define the role of spontaneous or vaccine-induced OY-TES-1 immunity on the course of EOC.

In conclusion, although the tissue restricted expression of OY-TES-1 is not as tight as other CT antigens, it could still represent a potential target for active specific immunotherapy in EOC because of aberrant expression in a high proportion of EOC patients and inherent immunogenicity. The role of $O Y$ TES-1 in tumor progression, if any, remains to be elucidated. Also, the fact that $O Y-T E S-1$, like many tumor antigens, is expressed only in a subset of patients with EOC underlines the need for identifying other antigens that could serve as targets for immunotherapy. To that end, we have continued with extensive analysis of CT antigens in EOC to uncover additional antigenic targets for polyvalent vaccine development.

\section{Acknowledgements}

This study was supported by the Cancer Research Institute/ Ludwig Institute for Cancer Research Cancer Vaccine Collaborative Grant. Dr Kunle Odunsi is supported by the Cancer Research Institute's Anna-Marie Kellen Clinical Investigator Award.

\section{References}

1. Greenlee RT, Hill-Harmon MB, Murray T and Thun M: Cancer statistics, 2001. CA Cancer J Clin 51: 15-36, 2001.

2. Engel J, Eckel R, Schubert-Fritschle G, et al: Moderate progress for ovarian cancer in the last 20 years: prolongation of survival, but no improvement in the cure rate. Eur J Cancer 38: 2435-2445, 2002.

3. Brichard V, Van Pel A, Wolfel T, et al: The tyrosinase gene codes for an antigen recognized by autologous cytolytic $\mathrm{T}$ lymphocytes on HLA-A2 melanomas. J Exp Med 178: 489-495, 1993.

4. Scanlan MJ, Chen YT, Williamson B, et al: Characterization of human colon cancer antigens recognized by autologous antibodies. Int J Cancer 76: 652-658, 1998.

5. Cheever MA, Disis ML, Bernhard H, et al: Immunity to oncogenic proteins. Immunol Rev 145: 33-59, 1995.

6. Tindle RW: Human papillomavirus vaccines for cervical cancer. Curr Opin Immunol 8: 643-650, 1996.

7. Boon $T$ and van der Bruggen P: Human tumor antigens recognized by T lymphocytes. J Exp Med 183: 725-729, 1996.

8. Chen YT, Scanlan MJ, Sahin U, et al: A testicular antigen aberrantly expressed in human cancers detected by autologous antibody screening. Proc Natl Acad Sci USA 94: 1914-1918, 1997.

9. Ono T, Kurashige T, Harada N, et al: Identification of proacrosin binding protein sp32 precursor as a human cancer/testis antigen. Proc Natl Acad Sci USA 98: 3282-3287, 2001.

10. Zendman AJ, Ruiter DJ and van Muijen GN: Cancer/testisassociated genes: identification, expression profile, and putative function. J Cell Physiol 194: 272-288, 2003.

11. Kirkin AF, Dzhandzhugazyan KN and Zeuthen J: Cancer/testis antigens: structural and immunobiological properties. Cancer Invest 20: 222-236, 2002.

12. Scanlan MJ, Simpson AJ and Old LJ: The cancer/testis genes: review, standardization, and commentary. Cancer Immun 4: 1, 2004.

13. Odunsi K, Jungbluth AA, Stockert E, et al: NY-ESO-1 and LAGE-1 cancer-testis antigens are potential targets for immunotherapy in epithelial ovarian cancer. Cancer Res 63: 6076-6083, 2003.

14. Yamada A, Kataoka A, Shichijo S, et al: Expression of MAGE1, MAGE-2, MAGE-3/-6 and MAGE-4a/-4b genes in ovarian tumors. Int J Cancer 64: 388-393, 1995.

15. Yakirevich E, Sabo E, Lavie O, Mazareb S, Spagnoli GC and Resnick MB: Expression of the MAGE-A4 and NY-ESO-1 cancer-testis antigens in serous ovarian neoplasms. Clin Cancer Res 9: 6453-6460, 2003.

16. Tammela J, Jungbluth AA, Qian F, et al: SCP-1 cancer/testis antigen is a prognostic indicator and a candidate target for immunotherapy in epithelial ovarian cancer. Cancer Immun 4: 10,2004

17. Baba T, Azuma S, Kashiwabara S and Toyoda Y: Sperm from mice carrying a targeted mutation of the acrosin gene can penetrate the oocyte zona pellucida and effect fertilization. J Biol Chem 269: 31845-31849, 1994. 
18. Serov SF, Scully RE and Sobin LH: Histological typing of ovarian tumors. International Classification of Tumors. World Health Organization, 1973.

19. Dippold WG, Lloyd KO, Li LT, Ikeda H, Oettgen HF and Old LJ: Cell surface antigens of human malignant melanoma: definition of six antigenic systems with mouse monoclonal antibodies. Proc Natl Acad Sci USA 77: 6114-6118, 1980.

20. Stockert E, Jager E, Chen YT, et al: A survey of the humoral immune response of cancer patients to a panel of human tumor antigens. J Exp Med 187: 1349-1354, 1998.

21. Kaplan EL and Meier P: Non-parametric estimation from incomplete observations. J Am Statist Assoc 53: 457-486, 1958.

22. Cox DR: Regression models and life-tables. J Royal Stat Soc 34: 187-220, 1972.

23. Burnet M: Cancer: a biological approach. III. Viruses associated with neoplastic conditions. IV. Practical applications. Br Med J: 841-847, 1957.
24. Zhang L, Conejo-Garcia JR, Katsaros D, et al: Intratumoral T cells, recurrence, and survival in epithelial ovarian cancer. $\mathrm{N}$ Engl J Med 348: 203-213, 2003.

25. Sato E, Olson SH, Ahn J, et al: Intraepithelial $\mathrm{CD}^{+}$tumor infiltrating lymphocytes and high $\mathrm{CD} 8^{+} /$Treg ratio are associated with favorable prognosis in epithelial ovarian cancer. Proc Natl Acad Sci USA 102: 1538-1543, 2005.

26. Tammela J, Jungbluth AA, Qian F, et al: SCP-1 'cancer/testis' antigen is a prognostic indicator and a candidate target for immunotherapy in epithelial ovarian cancer. Cancer Immun (In Press).

27. Jager E, Nagata Y, Gnjatic S, et al: Monitoring CD8 T cell responses to NY-ESO-1: correlation of humoral and cellular immune responses. Proc Natl Acad Sci USA 97: 4760-4765, 2000.

28. Kubuschok B, Xie X, Jesnowski R, et al: Expression of cancer testis antigens in pancreatic carcinoma cell lines, pancreatic adenocarcinoma and chronic pancreatitis. Int J Cancer 109: $568-575,2004$. 